\title{
NOTES
}

\section{Preparation and Properties of Polyamides Bearing Mesogenic Oligomers}

\author{
Kazuo Sugryama, ${ }^{\dagger}$ Tetsuo Oda, ${ }^{*}$ and Yoshikuni Yoshimitsu** \\ Department of Industrial Chemistry, Faculty of Engineering, Kinki University, \\ 1 Umenobe, Takaya, Higashi Hiroshima-shi, Hiroshima 729-17, Japan \\ *Hiroshima National College of Maritime Technology, 1-4272 Higashinocho, \\ Toyota-gun, Hiroshima 725-02, Japan \\ **Western Industrial Research Institute of Hiroshima, 2-10-1 Agaminami, \\ Kure-shi, Hiroshima 737, Japan
}

(Received January 27, 1993)

KEY WORDS Phosphorylation Polycondensation / Aromatic Polyamides / Liquid Crystalline Macromonomer / Graft Copolymer /

A number of workers has made a significant effort on the design of the architecture of liquid crystalline polymer (LCP) to control solubility $^{1,2}$ and melting behavior ${ }^{3,4}$ as well as the overall mechanical properties, ${ }^{5,6}$ using proper methods such as random- ${ }^{7}$ or block copolymer, ${ }^{8}$ combined main chain/side chain polymer, ${ }^{9}$ blending of rigid and flexible polymers. ${ }^{10}$ On the other hand, rod-like polyamides such as poly ( $p$-aminobenzoic acid) (PABA) and poly ( $p$-phenyleneterephthalamide) are known as fibers with high strength, high modulus, and heat resistance. These rod-like aromatic polyamides are also needed to improve their infusibility, limited solubility and compatibility with other polymers. In order to improve these intractable properties, a variety of concepts has also been developed. ${ }^{11,12}$

Recently, synthesis of block and graft copolymers containing liquid-crystalline segments was found to be a useful method for the preparation of tailored LCP. ${ }^{13-18}$ As part of our work on the synthesis and properties of LCP, ${ }^{19-23}$ our interest was focused on how the properties of non-thermotropically aromatic polyamide containing PABA segment

$\dagger$ To whom correspondence should be addressed. with a rod-like character can be changed by introducing the liquid crystalline oligomer in the side chain. The present note describes the synthesis and the characterization of graft copolymers composed of polyamide and liquid crystalline oligomers, polyamides $2 \mathbf{a}-\mathbf{e}$, obtained from the macromonomer technique. ${ }^{14}$

\section{EXPERIMENTAL}

Synthesis of $\omega$-Hydro-poly[1-(4-methoxyphenylazophenoxyhexyloxycarbonyl)-1methylethylene] thiomalic Acid (LCMac)

Twenty milliliters of tetrahydrofuran (THF) solution containing $5.95 \mathrm{~g}(15 \mathrm{mmol})$ of 4 methoxy-4'-(6-methacryloyloxyhexyloxy)azobenzene (MMAB: K 74 N 76 I), ${ }^{23} 0.34 \mathrm{~g}(2.25$ $\mathrm{mmol})$ of thiomalic acid, and $0.0246 \mathrm{~g}(0.15$ mmol) of AIBN in a glass tube was degassed by the freeze-thaw technique using a dryice/methanol bath and sealed in vacuo. After polymerization at $50^{\circ} \mathrm{C}$ for $8 \mathrm{~h}$, the contents of the tube were poured into a large amount of petroleum ether to precipitate LCMac. LCMac was isolated from the crude product by fractionation using THF-petroleum ether 
solvent system: yield $5.19 \mathrm{~g}(87.3 \%)$. The THF solution of LCMac was neutralized with $0.01 \mathrm{~mol} \mathrm{1}^{-1}$ of aqueous potassium hydroxide using phenolphthalein as an indicator, and from the value of neutralization the molecular weight was calculated to be 3600 . The molecular weight was also estimated to be $M_{n}=3400$ with a polydispersity $M_{w} / N_{n}=1.04$ by means of GPC measurement using polystyrene standard.

\section{Synthesis of Polyamides $2 \boldsymbol{a}-\boldsymbol{e}$}

Into a $100 \mathrm{~cm}^{3}$ round bottomed flask were placed $0.56 \mathrm{mmol}$ of LCMac, $2.78 \mathrm{mmol}$ of $p$-aminobenzoic acid (ABA), $0.56 \mathrm{mmol}$ of aromatic diamine, $5.60 \mathrm{mmol}$ of triphenyl phosphite (TPP), and $2.33 \mathrm{mmol}$ of $\mathrm{LiCl}$ in $6 \mathrm{ml}$ of pyridine (Py) and $24 \mathrm{ml}$ of $\mathrm{N}$-methyl-2pyrrolidone (NMP). After the solution was stirred and refluxed at $100^{\circ} \mathrm{C}$ under nitrogen for $6 \mathrm{~h}$, the reaction mixture was poured into a large amount of methanol to precipitate polyamides $\mathbf{2 a}-\mathbf{e}$. Polyamides $\mathbf{2 a}-\mathbf{e}$ were purified by removing low molecular weight compounds by use of a Soxhlet extractor with ethanol as solvent for $20 \mathrm{~h}$. A series of polyamides 1a-e was also prepared from succinic acid, ABA, and aromatic diamines by the same procedure as that of polyamides $2 a-\mathbf{c}$

\section{Measurements}

GPC analysis was conducted in THF solution with TSK gel $\mathrm{G}(4+3+2) \mathrm{HxL}$, using a TOSOH HPLC-8020 apparatus. The degree of crystallinity $(X)$ was measured on powder samples by diffraction of Mac science co. type MXP $18 \mathrm{~V}$ using $\mathrm{Cu}-K_{\alpha}$ radiation. The scattering intensity was registered at $2^{\circ} \mathrm{min}^{-1}$ for values of $2 \theta$ ranging from $4^{\circ}$ to $40^{\circ}$. Phase transition temperature was determined by DSC, using a Rigaku Thermoflex apparatus DSC-8230B. Sample quantity was $10 \mathrm{mg}$ with $10^{\circ} \mathrm{Cmin}^{-1}$ of heating and cooling rate. Pyrolysis was carried out with a Rigaku TG-DSC instrument standard type CN8076E1 .
Polarized optical microscopy (POM) of thin samples, which sandwiched between two glass slides (spacing, $12 \mu \mathrm{m}$ ), was performed using an Olympus microscope BH-2 with a heating stage attached to a temperature controller.

\section{RESULTS AND DISCUSSION}

The dicarboxyl-terminated liquid crystalline macromonomer, LCMac, was obtained by radical polymerization of MMAB initiated by AIBN in the presence of TMA as a chain transfer agent. According to DSC and POM, the mesophase of LCMac showed an enantiotropic liquid crystalline mesophase with a schlieren texture and was identified as a nematic phase: K 88N121 I. Recently, a direct polycondensation reaction using TPP and $\mathrm{LiCl}$ was found to be a useful method for the preparation of aromatic polyamides by combination of diamines and dicarboxylic diacids. ${ }^{24-26} \mathrm{We}$ applied the phosphorylation polyamidation to the preparation of polyamides $\mathbf{2 a}-\mathbf{e}$ with the molar ratio $1: 1: 5$ for diamine : LCMac: ABA in feed using TPP-LiCl-Py system as shown in Scheme 1. The polycondensation proceeded in a homogeneous NMP solution, while the condensation of succinic acid, aromatic diamines, and ABA did heterogeneously to give the parent polyamides $1 \mathrm{a}-\mathbf{e}^{27}$ The results of polycondensation are summarized in Table I. Polyamides 2 are obtained in an inadequate yield with small molecular weight even though the reaction proceed homogeneously. This could be explained as follows. The phosphor-

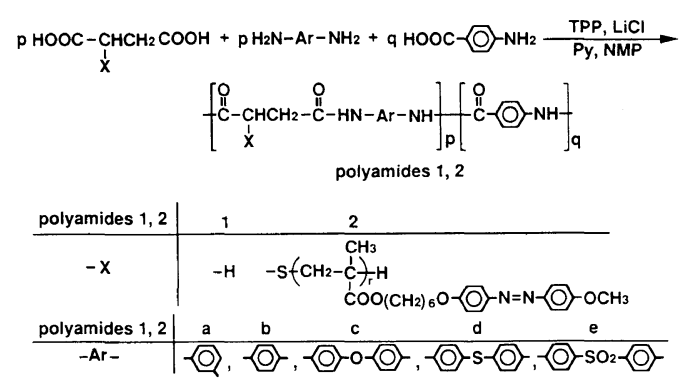

Scheme 1. Structure of polyamides 1, 2. 
Table I. Characteristic of polyamides $\mathbf{1 a}-\mathbf{e}$ and polyamides $\mathbf{2 a}-\mathbf{e}$

\begin{tabular}{|c|c|c|c|c|c|c|c|c|c|c|c|}
\hline \multirow{3}{*}{1,2} & \multirow{3}{*}{$\begin{array}{l}\text {-Ar- } \\
\text { indiamine }\end{array}$} & \multicolumn{2}{|c|}{$1^{\mathrm{a}}$} & \multicolumn{8}{|c|}{$2^{b}$} \\
\hline & & \multirow{2}{*}{$\frac{[\eta]}{d l g^{-1}}$} & \multirow{2}{*}{$\frac{X^{\mathrm{c}}}{\%}$} & \multirow{2}{*}{$\frac{\text { Yield }}{\%}$} & \multicolumn{2}{|c|}{ Mol. weight ${ }^{d}$} & \multirow{2}{*}{$\frac{X^{\mathrm{c}}}{\%}$} & \multicolumn{2}{|c|}{$\begin{array}{l}\text { Phase transition } \\
\text { temperature }^{\mathrm{e}}\end{array}$} & \multicolumn{2}{|c|}{ Decomposition $^{\mathrm{f}}$} \\
\hline & & & & & $M_{n}$ & $M_{w}$ & & $T_{\mathrm{m}} /{ }^{\circ} \mathrm{C}$ & $T_{\mathrm{i}} /{ }^{\circ} \mathrm{C}$ & $T_{\text {int }} /{ }^{\circ} \mathrm{C}$ & $T_{\max } /{ }^{\circ} \mathrm{C}$ \\
\hline $\mathbf{a}$ & & 0.49 & 11.5 & 72.0 & 6900 & 8000 & 4.4 & 84.7 & 126.0 & 317 & 528 \\
\hline b & & 0.53 & 23.5 & 71.1 & 6500 & 7600 & 3.9 & 86.4 & 135.9 & 319 & 532 \\
\hline c & & 0.47 & 16.5 & 75.1 & 7900 & 10000 & 3.9 & 88.8 & 133.9 & 319 & 554 \\
\hline d & & 0.42 & 16.5 & 72.7 & 6400 & 7400 & 4.3 & 82.2 & 121.3 & 319 & 531 \\
\hline $\mathbf{e}$ & & 0.38 & 8.2 & 64.5 & 5800 & 6700 & 4.8 & 89.5 & 127.7 & 320 & 550 \\
\hline
\end{tabular}

a Obtained $81-90 \%$ in yield.

b $\mathrm{H}_{2} \mathrm{~N}-\mathrm{Ar}-\mathrm{NH}_{2}, 0.56 \mathrm{mmol}$; LCMac, $0.56 \mathrm{mmol}$; ABA, $2.78 \mathrm{mmol}$; TPP, $5.60 \mathrm{mmol} ; \mathrm{LiCl}, 2.33 \mathrm{mmol} ; \mathrm{Py}, 6 \mathrm{ml}$; $\mathrm{NMP}, 24 \mathrm{ml}, 100^{\circ} \mathrm{C}, 6 \mathrm{~h}$.

c Crystallinity calculated from powder WAXS.

d Measured by GPC with THF as an eluent and calibrated with standard polystyrene.

e $T_{\mathrm{m}}$ and $T_{\mathrm{i}}$ represent melting point and isotropization transition of grafted LCMac part, respectively.

f $T_{\mathrm{int}}$ and $T_{\max }$ represent initial and maximum decomposition temperatures, respectively.

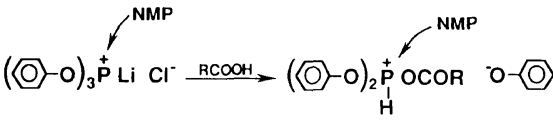

$$
\begin{aligned}
& \text { (A) } \\
& \stackrel{\mathrm{R}^{\prime} \mathrm{NH}_{2}}{\longrightarrow} \mathrm{RCONHR}^{\prime}+\left(\langle\mathrm{O}-\mathrm{O})_{2} \underset{\mathrm{H}}{\mathrm{P}}=\mathrm{O}+(\mathrm{O}-\mathrm{OH}\right.
\end{aligned}
$$

Scheme 2. Structure of phosphonium salts.

ylation polyamidation of ABA using TPP$\mathrm{LiCl}$ system was markedly affected by solvents and the most favorable results being given in NMP and $N, N$-dimethylacetamide (DMAc). ${ }^{24}$ Higashi $^{24}$ proposed that $\mathrm{C}=\mathrm{O}$ groups of the solvents have some effect upon the formation and reactivity of phosphonium salts (A) and/or acyloxy phosphonium salts (B) which produced during the reaction (Scheme 2). In our case, the ester groups of oligomeric methacrylates presented around the reaction site may prevent or reduce such the effect of NMP. Polyamides 2a-e were characterized using IR and GPC. The IR spectrum of polyamide $2 \mathbf{c}$, as a typical

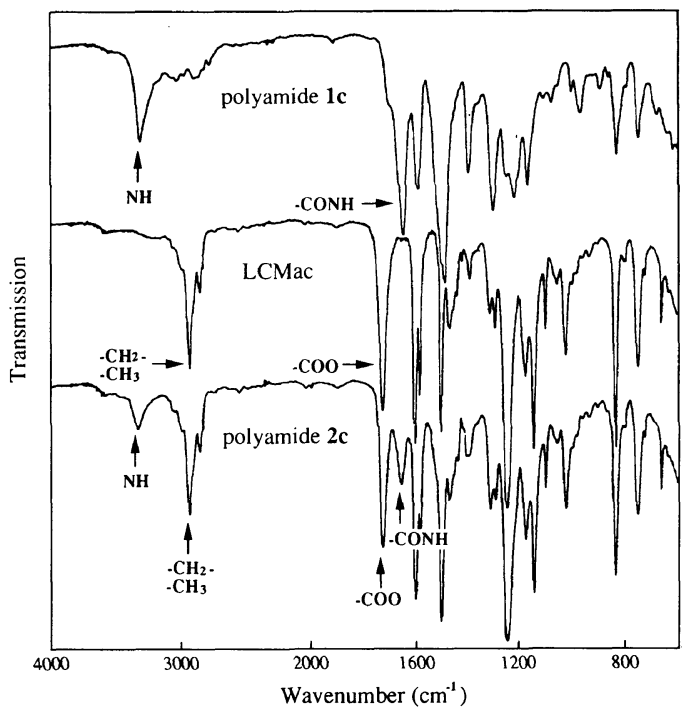

Figure 1. IR spectra of polyamides 1c, 2c, and LCMac.

instance, is shown in Figure 1 together with those for polyamide 1c and LCMac for comparison. The presence of the amide and ester groups in polyamides $\mathbf{2 a}-\mathbf{e}$ was revealed 


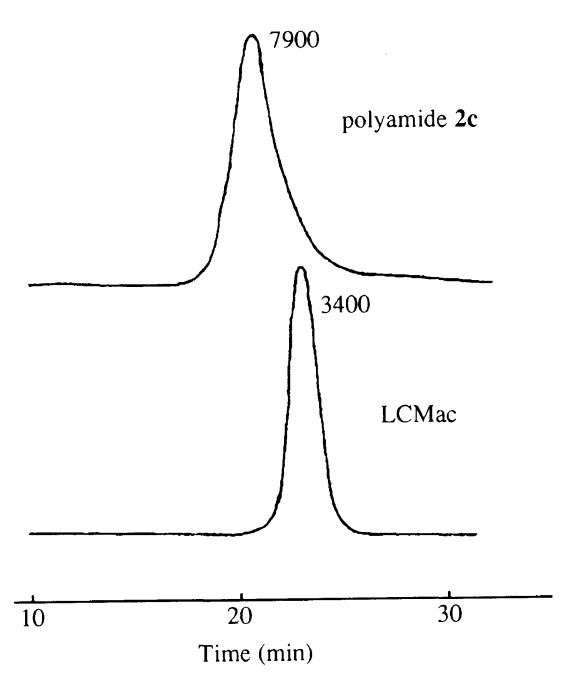

Figure 2. GPC curves of polyamide $2 \mathrm{c}$ and LCMac.

by specific absorption of $\mathrm{N}-\mathrm{H}$ stretch in $3330-3350 \mathrm{~cm}^{-1}, \mathrm{C}=\mathrm{O}$ stretch of ester in $1720-1730 \mathrm{~cm}^{-1}$, and $\mathrm{C}=\mathrm{O}$ stretch of amide linkage in $1650-1660 \mathrm{~cm}^{-1}$. Polyamides $2 \mathrm{a}-$ e, therefore, exhibit the sum of absorption of the polyamide segment and grafted LCMac parts. The molecular weight of polyamides 2a-e measured by GPC with polystyrene standard, $M_{w}$, was found to be $6700-10000$ with $M_{w} / M_{n}=1.15-1.27$ as tabulated in Table I. As shown in Figure 2, polyamide $2 \mathbf{c}$ revealed an unimodal molecular weight distribution (corresponding to $M_{w}$ of 7900) at a higher elution volume than the one for LCMac $\left(M_{w}\right.$, 3600). The results support the composition of polyamides $\mathbf{2 a}-\mathbf{e}$ shown in Scheme 1. From the wide-angle $\mathrm{X}$-ray scattering (WAXS) measurements it was observed that an increase in the degree of crystallinity $(X)$ caused by substituting the aromatic diamines from bending to linear form in polyamides $1 \mathbf{a}-\mathbf{e}$. The $X$ value of polyamides $\mathbf{2 a}-\mathbf{c}$ was found to be lower than that of polyamides $\mathbf{1 a}-\mathbf{c}$ because of grafting of liquid crystalline oligomers onto parent polyamide. Thermal properties of polyamides $\mathbf{2 a}-\mathbf{e}$ were studied by DSC and POM as well as TG-DTA. DSC measurements were performed at temperature
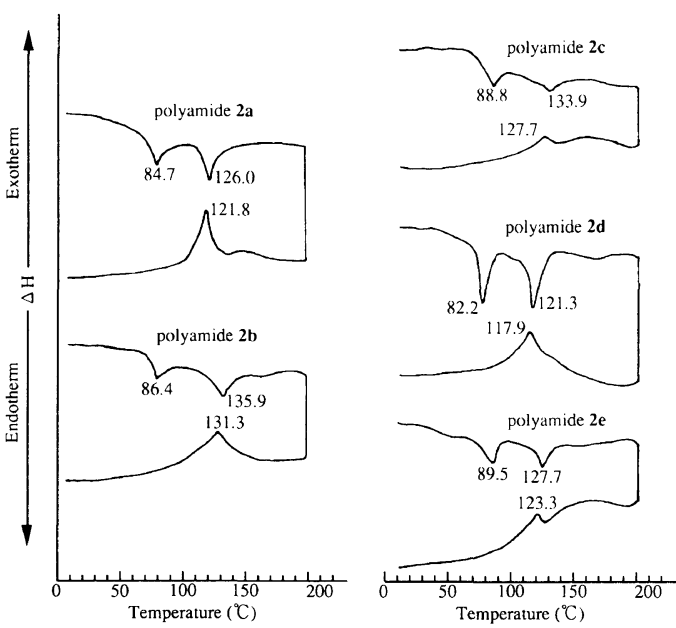

Figure 3. DSC thermograms of polyamides $\mathbf{2 a}-\mathbf{e}$.

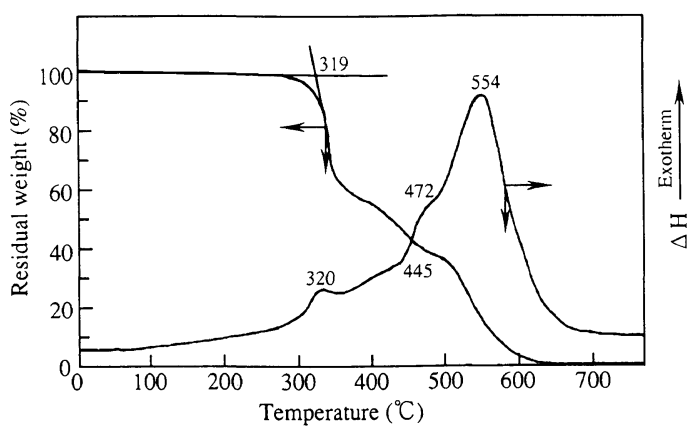

Figure 4. TG-DTA of polyamide $\mathbf{2 c}$.

between 20 and $200^{\circ} \mathrm{C}$ as shown in Figure 3. The melting process of polyamide $\mathbf{2 c}$, for instance, indicated by two endothermic peaks at $88.8^{\circ} \mathrm{C}$ (melting point) and $133.9^{\circ} \mathrm{C}$ (isotropization transition) is followed by decomposition begun at $319^{\circ} \mathrm{C}$. After annealed at the temperature below decomposition for $1 \mathrm{~h}$, polyamide $2 \mathrm{c}$ exhibits a broad exothermic peak due to crystallizing transition on cooling. POM of polyamide $2 \mathrm{c}$ reveals a birefringence similarly to the texture of LCMac. Similar birefringence was observed on the other polyamide 2 . POM of polyamide $2 \mathrm{c}$ also showed a small twinkling sand like texture due to polyamide segments in dark at a temperature above isotropization transition of grafted LCMac part. Further investigation on the 
microphase-separated biphasic structure of polyamides $\mathbf{2 a}-\mathbf{e}$ is in progress. The thermal stability of polyamides $\mathbf{2 a}$ - e was studied by TG-DTA measurements in air. Figure 4 shows a TG-DTA curve of polyamide $\mathbf{2} \mathbf{c}$ as a typical instance. Polyamides 2a-e degrade via a multi-step mechanism including the decomposition of the oligomeric side chains at temperature near $320^{\circ} \mathrm{C}$ and polyamide backbones at $530-550^{\circ} \mathrm{C}$, whereas polyamides 1a - e degrade with maximum degradation at around $540^{\circ} \mathrm{C}$ through a random fission of the polymer backbone before their melting occur. ${ }^{27}$ Thermal properties of polyamides $\mathbf{2 a}-\mathbf{e}$ were listed in Table I. The introduction of PABA as hard segments was found to result in an increase in thermal stability of polymers. From the solubility test of polyamides $1 \mathbf{a}-\mathbf{e}$, neither solubility nor swelling was observed in common organic solvent other than hexamethylphosphoramide, DMAc- $\mathrm{LiCl}$ system, and sulfuric acid. On the other hand, polyamides $\mathbf{2 a}-\mathbf{e}$ were soluble in a variety of solvents such as $N, N$-dimethylformamide, DMAc, NMP, dimethyl sulfoxide, and even in THF and dichloromethane. High solubility of them is considered to be attributed to the introduction of liquid crystalline oligomers along polyamides $1 \mathbf{a}-\mathbf{e}$ backbone.

\section{REFERENCES AND NOTES}

1. R. Sinta, R. A. Minns, R. A. Gaudiana, and H. G. Rogers, J. Polym. Sci., C, Polym. Lett., 25, 11 (1987).

2. W. Hatke, H.-W. Schmidt, and W. Heitz, J. Polym. Sci., Polym. Chem., 29, 1387 (1991).

3. J. M. G. Gowie and H. H. Wu, Makromol. Chem., 189, 1511 (1988).
4. H. R. Kricheldorf, I. Beuermann, and G. Schwarz, Makromol. Chem. Rapid Commun., 10, 211 (1989).

5. W. J. Jackson, Jr. and H. F. Kuhfuss, J. Polym. Sci., Polym. Chem. Ed., 14, 2043 (1976).

6. J. E. Mclntyre, P. E. P. Maj, S. A. Sills, and J. G. Tomka, Polymer, 29, 1095 (1988).

7. V. Percec and Y. Tsuda, Macromolecules, 23, 5(1990).

8. J. Y. Jadhav, W. R. Krigbaum, A. Ciferri, and J. Preston, J. Polym. Sci., C, Polym. Lett., 27, 59 (1989).

9. B. W. Endres, M. Ebert, J. H. Wendorff, B. Reck, and H. Ringsdorf, Liq. Cryst., 7, 217 (1990).

10. W. H. Jo, H. Yim, I. H. Kwon, and T. W. Son, Polym. J., 24, 519 (1992).

11. N. Ogata, K. Sanui, and H. Itaya, Polym. J., 22, 85 (1990).

12. References therein ref 2 .

13. C. Pugh and V. Perec, Polym. Prepr., Am. Chem. Soc., Div. Polym. Chem., 27, 366 (1986).

14. Y. Chujo, H. Kobayashi, and Y. Yamashita, Polym. J., 20, 407 (1988).

15. A. Gottschalk and H.-W. Schmidt, Liq. Cryst., 5, 1619 (1989).

16. M. Sato, T. Kobayashi, F. Komatsu, and N. Takeno, Makromol. Chem. Rapid Commun., 12, 269 (1991).

17. T. Heitz and O. W. Webster, Makromol. Chem., 192, 2463 (1991).

18. M. Hefft and J. Springer, Makromol. Chem., 193, 329 (1992).

19. K. Sugiyama and K. Shiraishi, J. Polym. Sci., Polym. Chem. Ed., 28, 1983 (1990).

20. K. Sugiyama, K. Kato, and K. Shiraishi, Bull. Chem. Soc. Jpn., 65, 2259 (1992).

21. K. Sugiyama, K. Shiraishi, T. Nakaya, Y. Yoshimitsu, and T. Ohashi, Chem. Express, 7, 289 (1992).

22. K. Sugiyama, K. Kato, and K. Shiraishi, Polym. J., 25, 103 (1993).

23. K. Sugiyama and K. Shiraishi, Bull. Chem. Soc. Jpn., 64, 1715 (1991).

24. F. Higashi, M. Goto, and H. Kakinoki, J. Polym. Sci., Polym. Chem. Ed., 18, 1711 (1990).

25. C.-P. Yang, J.-M. Cheng, and S.-H. Hsiao, Makromol. Chem., 193, 445 (1992).

26. C.-P. Yang and W.-T. Chen, Makromol. Chem., 193, 2323 (1992).

27. Detailed characterization and properties of polyamides 1a $\mathbf{e}$ will be reported elsewhere. 